\title{
PENYULUHAN HUKUM DAN PENDAMPINGAN KEPESERTAAN JAMINAN SOSIAL TENAGA KERJA SEKTOR INFORMAL KELOMPOK TANI "SUMBER REJO" DESA TUWANG KECAMATAN KARANGANYAR KABUPATEN DEMAK
}

\author{
Siti Ummu Adillah ${ }^{1 *}$, Amin Purnawan ${ }^{2}$, dan Siti Rodhiyah Dwi Istina ${ }^{3}$ \\ ${ }^{1,3}$ Prodi Magister Ilmu Hukum, Fakultas Hukum, UNISSULA, Semarang, Indonesia \\ ${ }^{2}$ Prodi Magister Kenotariatan, Fakultas Hukum, UNISSULA, Semarang, Indonesia \\ *Corresponding Author \\ Jl. Raya Kaligawe KM. 4 Semarang, Jawa Tengah, Indonesia \\ Telp. (+6224) 6583584, Fax (+6224) 6582455 \\ E-mail: ummu@unissula.ac.id
}

\begin{abstract}
This community service aims to provide knowledge and understanding of employment social security for workers in the informal sector, such as: Doctors, Advocates, Traders, Fishermen, Farmers, Ojek Workers, Becak Workers, and so on, especially for the Tuwang Village "Sumber Rejo" Farmer Group. Karanganyar District, Demak Regency. This community service is expected to provide knowledge and insight to the farming community about the importance of work safety, which in turn is expected to raise awareness to obtain legal protection for labor social security for farmers at work. The method used in this community service is to provide counseling and assistance, through lectures and discussions, which will then be followed up by assisting the farming community to become a participant in employment social security. The results and discussion were community service by providing legal counseling and assistance to farmer groups "Sumber Rejo" regarding the importance of being a participant in the Social Security Workforce for the Informal Sector like farmers, to anticipate work accidents, old age or death.
\end{abstract}

Keywords: Participation, Labor Social Security, Informal Sector.

\begin{abstract}
Abstrak
Pengabdian masyarakat ini bertujuan untuk memberikan pengetahuan dan pemahaman tentang jaminan sosial ketenagakerjaan bagi pekerja di sektor informal, seperti: Dokter, Advokat, Pedagang, Nelayan, Petani, Tukang Ojek, Tukang Becak, dan sebagainya, khusunya bagi Kelompok Tani “Sumber Rejo" Desa Tuwang Kecamatan Karanganyar Kabupaten Demak. Pengabdian masyarakat ini diharapkan dapat memberikan pengetahuan dan wawasan kepada masyarakat tani tentang pentingnya keselamatan kerja, yang pada akhirnya diharapkan dapat menimbulkan munculnya kesadaran untuk mendapatkan perlindungan hukum atas jaminan sosial ketenagakerjaan terhadap petani pada saat bekerja. Metode yang digunakan dalam pengabdian masyarakat ini adalah dengan melakukan penyuluhan dan pendampingan, melalui metode ceramah dan diskusi, yang selanjutnya akan ditindaklanjuti dengan melakukan pendampingan dibantu oleh kepada masyarakat tani untuk menjadi peserta jaminan sosial ketenagakerjaan. Hasil dan pembahasan yaitu pengabdian masyarakat dengan melakukan penyuluhan hukum dan pendampingan terhadap kelompok tani "Sumber Rejo" tentang pentingnya menjadi peserta Jaminan Sosial Tenaga Kerja bagi Sektor Informal sperti petani, untuk mengantisipasi terjadinya kecelakaan kerja, memasuki usia tua ataupun kematian.
\end{abstract}

Kata Kunci: Kepesertaan, Jaminan Sosial Tenaga Kerja, Sektor Informal.

\section{PENDAHULUAN}

Tujuan utama pelaksanaan PKM, yaitu dapat meningkatkan kesejahteraan mitra (kelompok tani), melalui kepesertaan jaminan sosial ketenagakerjaan. Petani merupakan pekerja di sektor informal atau dalam istilah BPJS Ketenagakerjaan termasuk kategori pekerja bukan penerima upah (BPU), yang perlu difikirkan keselamatannya di saat menuju tempat bekerja, saat 
bekerja maupun saat perjalanan pulang kerja. Para petani perlu mendapatakan perlindungan jaminan sosial ketenagakerjaan.

Di dalam Pasal 28 H ayat (3) UUD 1945, menekankan bahwa "Setiap orang berhak atas jaminan sosial yang memungkinkan pengembangan dirinya secara utuh sebagai manusia yang bermartabat". Jaminan sosial adalah salah satu bentuk perlindungan sosial untuk menjamin seluruh rakyat agar dapat memenuhi kebutuhan dasar hidupnya yang layak. (Pasal 1 ayat (1) Undang-Undang Sistem Jaminan Sosial Nasional). Dasar hukum tentang hak atas pekerjaan dan hak atas jaminan sosial bagi setiap warga Negara, secara eksplisit sudah diatur sebagai berikut:

Berdasarkan Pasal 1 angka 31 Undang-Undang Ketenagakerjaan menyatakan bahwa kesejahteraan pekerja/buruh adalah suatu pemenuhan kebutuhan dan/atau keperluan yang bersifat jasmaniah dan rohaniah, baik di dalam maupun di luar hubungan kerja, yang secara langsung atau tidak langsung dapat mempertinggi produktivitas kerja dalam lingkungan kerja yang aman dan sehat. Menurut Pasal 99 ayat (1) Undang-Undang Ketenagakerjaan "Setiap pekerja/buruh dan keluarganya berhak untuk memperoleh jaminan sosial tenaga kerja". Dalam ketentuan tersebut jaminan sosial tenaga kerja merupakan suatu hak yang tidak hanya dimiliki oleh pekerja/buruh tetapi juga keluarga. Pemberian hak kepada pekerja ini dimaksudkan untuk memberikan jaminan pelayanan bila ada anggota keluarga pekerja mengalami sakit atau memerlukan bantuan medis lain seperti hamil dan melahirkan serta mereka yang mendapatkan kecelakaan kerja. (Maimun, 2004).

Kesejahteraan yang perlu dikembangkan bukan hanya bagi tenaga kerja itu sendiri, melainkan juga bagi keluarganya dalam rangka meningkatkan kesejahteraan masyarakat. Dalam arti luas, yang harus tetap dipelihara termasuk pada saat pekerja kehilangan sebagian atau seluruh penghasilannya sebagai akibat terjadinya risiko ekonomi dan risiko sosial antara lain kecelakaan kerja, sakit, meninggal dunia, cacat akibat kecelakaan kerja dan hari tua. Dalam keadaan hilang sama sekali, kehilangan kemampuan untuk memenuhi kebutuhan hidup bagi dirinya dan keluarganya. Oleh karena risiko ini bersifat universal, maka perlu dipecahkan secara sistematis, terencana, bertahap dan berkelanjutan (Siti Ummu Adillah, 2020).

"Jaminan sosial (security act) merupakan hak setiap warga negara yang dilindungi konstitusi”, seperti yang disebutkan dalam Pasal 41 ayat (1) Undang-Undang Nomor 39 Tahun 1999 tentang Hak Asasi Manusia, bahwa "Setiap warga negara berhak atas jaminan sosial yang dibutuhkan untuk hidup layak dan untuk perkembangan pribadinya secara utuh", namun kenyataannya belum seluruh warga negara mendapatkan akses jaminan sosial nasional tersebut. Jaminan sosial didesain untuk memberikan manfaat yang berarti bagi peserta, minimal memberikan jaminan terpenuhinya kebutuhan dasar yang layak bagi peserta dan anggota keluarganya. Skema penyelenggaraan jaminan sosial nasional tersebut selanjutnya dituangkan dalam peraturan perundang-undangan yakni Undang-Undang Nomor 24 Tahun 2011 tentang Badan Penyelenggara Jaminan Sosial (UU BPJS). BPJS merupakan lembaga atau badan hukum yang dibentuk untuk menyelenggarakan program jaminan sosial di Indonesia. Ada dua bentuk BPJS seperti yang dijelaskan dalam Pasal 5 ayat (2) UU BPJS bahwa Badan Penyelenggara Jaminan Sosial sebagaimana dimaksud pada ayat Pasal 5 ayat (1) UU BPJS adalah: a) BPJS Kesehatan; dan b) BPJS Ketenagakerjaan.

Sejak diundangkannya UU BPJS, maka jaminan sosial ketenagakerjaan di Indonesia menjadi domain BPJS Ketenagakerjaan. Namun UU BPJS tidak mengatur secara jelas perihal pekerja informal atau pekerja bukan penerima upah. UU BPJS hanya memahami pekerja sebagai "Setiap orang yang bekerja dengan menerima gaji, upah, atau imbalan dalam bentuk 
lain." (Pasal 1 angka 8 UU BPJS). Dalam UU BPJS tidak dibahas lebih lanjut perihal pekerja formal dan pekerja informal.

Hal ini berbeda dengan pemahaman pekerja yang terdapat dalam Undang-Undang Nomor 3 Tahun 1992 tentang Jaminan Sosial Tenaga Kerja (UU Jamsostek), dimana dalam Pasal 1 UU Jamsostek pengertian pekerja/tenaga kerja adalah setiap orang yang mampu melakukan pekerjaan, baik di dalam maupun di luar hubungan kerja, guna menghasilkan jasa atau barang untuk memenuhi kebutuhan masyarakat (Pasal 1 angka 2 UU Jamsostek). Berkaitan dengan tenaga kerja luar hubungan kerja yang disebut dalam UU Jamsostek, bisa diperoleh penjelasnya dalam Peraturan Menteri Tenaga Kerja dan Transmigrasi Nomor 24 Tahun 2006 tentang Pedoman Penyelenggaraan Program Jaminan Sosial Tenaga Kerja bagi Tenaga Kerja yang Melakukan Pekerjaan di Luar Hubungan Kerja yang mengacu pada UU Jamsostek. Disebutkan bahwa, "Tenaga kerja yang melakukan pekerjaan di luar hubungan kerja adalah tenaga kerja yang melakukan kegiatan ekonomi tanpa dibantu orang lain (berusaha sendiri tanpa buruh/pekerja)." Dalam penjelasan selanjutanya ditunjuk secara eksplisit bahwa tenga kerja jenis ini adalah, "Orang yang berusaha sendiri atau tenaga kerja yang melakukan pekerjaan di luar hubungan kerja pada umumnya melakukan usaha-usaha pada ekonomi informal."

Jumlah pekerja di Indonesia mayoritas bekerja di sektor informal. Berdasarkan data dari Badan Pusat Statistik (BPS) pada Agustus 2020 jumlah pekerja yang bekerja pada kegiatan informal berjumlah 77,68 juta orang atau (60,47 persen). Data ini menunjukkan bahwa tenaga kerja di Indonesia, lebih mendominasi bekerja di sektor informal. Dengan banyaknya pekerja yang berkegiatan di sektor informal, maka sudah sewajarnya kalau pemerintah memberikan perlindungan jaminan sosial ketenagakerjaan terhadap pekerja informal, sebagaimana yang termaktub di dalam Pasal $28 \mathrm{H}$ ayat (3) UUD 1945, bahwa "Setiap orang berhak atas jaminan sosial yang memungkinkan pengembangan dirinya secara utuh sebagai manusia yang bermartabat".

\section{METODE PELAKSANAAN}

Metode yang digunakan dalam pendampingan dan penyuluhan kepesertaan BPJS Ketenagakerjaan, meliputi beberapa tahapan, sebagai berikut:

1. Tahap Persiapan, pada tahap ini Tim Pengabdian Masyarakat mencari informasi melalui perangkat Desa Tuwang tentang keadaan petani di Desa Tuwang, setelah itu dengan perangkat Desa Tuwang, melakukan pemilihan dan penetapan kelompok Tani "Sumber Rejo" yang akan mendapatkan pendampingan dan penyuluhan, kemudian membuat kesepakatan agenda kegiatan dan waktu untuk pendampingan dan penyuluhan.

2. Tahap pelaksanaan kegiatan dilakukan secara terstruktur mengacu pada jadwal acara yang telah dibuat sebelumnya, yaitu acara dimulai dengan pembukaan, sambutan dari Kepala Desa Tuwang, Kecamatan Karanganyar, Kabupaten Demak, yang diwakili oleh perangkat Desanya, sambutan dari Tim Pengabdian Masyarakat dan kemudian dilanjutkan penyuluhan hukum, dengan metode ceramah dan diskusi tentang Sistem Jaminan Sosial Nasional (SJSN) dan BPJS Ketenagakerjaan, serta program-programnya atau manfaatnya. Acara pengabdian masyarakat ini didampingi oleh PERISAI, agar dapat langsung dilakukan pendampingan bagi para petani yang berminat untuk menjadi peserta Jaminan Sosial Ketenagakerjaan.

Kegiatan pengabdian kepada masyarakat ini menggunakan metode penyuluhan hukum (Edy Nurcahyo dkk, 2020: 118), yaitu menyuluh atau memberikan penjelasan tentang Jaminan Sosial Ketenagakerjaan kepada peserta yang hadir, kemudian ditindaklanjuti dengan 
Empowerment : Jurnal Pengabdian Masyarakat, e-ISSN 2598-2052

Vol. 04 Nomor 01. 2021.1-9.

pendampingan terhadap peserta yang berkeinginan menjadi peserta Jaminan Sosial Ketenagakerjaan.

\section{HASIL DAN PEMBAHASAN}

1. Pemahaman tentang BPJS Ketenagakerjaan adalah sebuah program jaminan sosial dan proteksi (perlindungan) yang ditujukan bagi pekerja Indonesia maupun pekerja asing yang bekerja di Indonesia sekurang-kurangnya enam bulan (Ali Hidayat, 2017).

2. Tujuan BPJS adalah untuk mewujudkan terselenggaranya pemberian jaminan, terpenuhinya kebutuhan dasar hidup yang layak bagi setiap Peserta dan/atau anggota keluarganya (Andre, 2020).

3. Program dan manfaat BPJS Ketenagakerjaan

\section{a. Jaminan Kecelakaan Kerja (JKK)}

Program JKK adalah jaminan atas risiko kecelakaan yang terjadi dalam hubungan kerja dimulai dari berangkat hingga pulang kerja dan penyakit akibat lingkungan kerja. Jaminan yang diberikan termasuk kecelakaan dalam perjalanan dari rumah ke tempat kerja dan sebaliknya.

Adapun jaminan dan manfaat dari program JKK adalah:

1) Perlindungan atas risiko kecelakaan kerja termasuk perjalanan pergi, pulang, dan di tempat bekerja, serta perjalanan dinas.

2) Perawatan tanpa batas biaya sesuai kebutuhan medis.

3) Santunan upah selama tidak bekerja akibat kecelakaan kerja (enam bulan pertama 100 persen, enam bulan kedua 75 persen, seterusnya hingga sembuh 50 persen).

4) Santunan kematian akibat kecelakaan kerja sebesar 48x upah yang dilaporkan oleh perusahaan atau peserta.

5) Bantuan beasiswa pendidikan bagi satu anak dari peserta yang meninggal dunia atau mengalami cacat total tetap akibat kecelakaan kerja sebesar Rp12 juta.

6) Bantuan untuk kesiapan kembali bekerja berupa pendampingan sejak dirawat di rumah sakit hingga bisa bekerja lagi.

7) Jika terjadi cacat sebagian permanen, pekerja akan mendapatkan pelatihan khusus agar tetap bisa kembali bekerja melalui penyempurnaan manfaat Jaminan Kecelakaan Kerja-Return To Work (JKK-RTW), di samping santunan cacat.

\section{b. Jaminan Hari Tua (JHT)}

Jaminan ini akan memberikan manfaat berupa uang tunai dari nilai akumulasi iuran ditambah hasil pengembangannya. Uang ini akan dibayarkan ketika peserta mencapai usia 56 tahun, meninggal dunia, atau mengalami cacat total tetap.

1) Manfaat JHT adalah berupa uang tunai yang besarnya merupakan nilai akumulasi iuran ditambah hasil pengembangannya, yang dibayarkan secara sekaligus apabila :

a) peserta mencapai usia 56 tahun

b) meninggal dunia

c) cacat total tetap

Yang dimaksud usia pensiun termasuk peserta yang berhenti bekerja karena mengundurkan diri, terkena PHK dan sedang tidak aktif bekerja dimanapun; atau peserta yang meninggalkan wilayah Indonesia untuk selamanya.

Hasil pengembangan JHT paling sedikit sebesar rata-rata bunga deposito counter rate bank pemerintah. 
2) Manfaat JHT sebelum mencapai usia 56 tahun dapat diambil sebagian jika mencapai kepesertaan 10 tahun dengan ketentuan sebagai berikut:

a) Diambil max $10 \%$ dari total saldo sebagai persiapan usia pensiun

b) Diambil max $30 \%$ dari total saldo untuk uang perumahan

Pengambilan sebagian tersebut hanya dapat dilakukan sekali selama menjadi peserta

3) Jika setelah mencapai usia 56 tahun peserta masih bekerja dan memilih untuk menunda pembayaran JHT maka JHT dibayarkan saat yang bersangkutan berhenti bekerja.

4) BPJS Ketenagakerjaan wajib memberikan informasi kepada peserta mengenai besarnya saldo JHT beserta hasil pengembangannya 1 (satu) kali dalam setahun.

5) Apabila peserta meninggal dunia, urutan ahli waris yang berhak atas manfaat JHT sbb:

a) Janda/duda

b) Anak

c) Orang tua, cucu

d) Saudara Kandung

e) Mertua

f) Pihak yang ditunjuk dalam wasiat

g) Apabila tidak ada ahli waris dan wasiat maka JHT dikembalikan ke Balai Harta Peninggalan.

h) Jika terjadi JHT kurang bayar akibat pelaporan upah yang tidak sesuai, menjadi tanggungjawab perusahaan.

\section{c. Jaminan Pensiun (JP)}

Jaminan pensiun adalah jaminan sosial yang bertujuan untuk kehidupan yang layak bagi peserta atau ahli warisnya dengan memberikan penghasilan setelah memasuki usia pensiun, cacat total tetap atau pindah secara permanen ke luar negeri berupa penghasilan bagi peserta ataupun ahli warisnya dan meninggal dunia.

\section{Manfaat yang diberikan dari program ini yaitu:}

1) Manfaat pensiun hari tua berupa uang tunai bulanan.

2) Manfaat pensiun janda/duda berupa uang bulanan yang diberikan kepada janda/duda yang menjadi ahli waris.

3) Manfaat pensiun cacat berupa uang tunai bulanan yang diberikan kepada peserta.

4) Manfaat pensiun anak berupa uang tunai bulanan kepada 2 orang anak (maksimal).

5) Manfaat pensiun orang tua diberikan kepada orang tua (bapak/ibu) yang menjadi ahli waris peserta lajang.

\section{d. Jaminan Kematian (JKM)}

Program yang memberikan jaminan bagi pekerja yang meninggal dunia bukan akibat dari kecelakaan kerja Atau Program JKM adalah asuransi jiwa yang memberikan santunan meninggal dunia kepada ahli waris atau keluarga pekerja yang terdaftar sebagai peserta BPJS Ketenagakerjaan.

Manfaat atau santunan yang diberikan dari program ini yaitu:

1) Santunan kematian berupa uang tunai.

2) Santunan berkala 24 bulan sebesar Rp200 ribu per bulan atau total Rp4,8 juta yang dibayar sekaligus.

3) Biaya pemakaman sebesar Rp3 juta. 
4) Bantuan beasiswa bagi satu orang anak yang ditinggalkan sebesar Rp12 juta (jika peserta telah memasuki usia kepesertaan 5 tahun).

5) Keseluruhan manfaat jaminan kematian yang diterima sebesar Rp36 juta.

\section{Peserta BPJS}

a. Peserta adalah: setiap orang termasuk orang asing yang bekerja minimal 6 (enam) bulan di Indonesia yang telah membayar iuran.

b. Peserta BPJS terdiri dari:

1) Pekerja penerima upah (PU), seperti: pekerja pada penyelenggara Negara dan pekerja bukan pada penyelenggara Negara.

2) Pekerja bukan penerima upah (BPU), seperti: pemberi kerja, Tenaga kerja mandiri, dan pekerja yang tidak menerima upah.

5. Siapa saja yang menjadi peserta BPJS Ketenagakerjaan?

Terdapat empat kategori yang bisa menjadi peserta BPJS Ketenagakerjaan. Siapa saja? Yuk simak ulasan berikut.

a. Pekerja penerima upah yaitu pekerja yang mendapatkan upah, gaji, atau imbalan dari pemberi kerja (perusahaan).

b. Pekerja bukan penerima upah yaitu pekerja yang mendapatkan penghasilan secara mandiri baik itu dengan menawarkan jasa atau barang.

c. Jasa konstruksi adalah pekerja yang terlibat dalam perencanaan, pelaksanaan, pekerjaan serta pengawasan proyek konstruksi baik itu pekerja kontrak, pekerja harian dengan dana pengerjaan proyek yang bersumber dari APBN/APBD, dana luar negeri, swasta, perorangan dan sumber dana lainnya.

d. Pekerja migran Indonesia yaitu warga negara Indonesia yang melakukan pekerjaan serta menerima upah dari luar wilayah Republik Indonesia (Lifepal, 2020).

6. Kepesertaan

a. Dapat mengikuti program BPJS Ketenagakerjaan secara bertahap dengan memilih program sesuai dengan kemampuan dan kebutuhan peserta.

b. Dapat mendaftar sendiri langsung ke Kantor Cabang BPJS Ketenagakerjaan atau mendaftar melalui wadah/kelompok/Mitra/Payment Point (Aggregator/Perbankan) yang telah melakukan Ikatan Kerja Sama (IKS) dengan BPJS Ketenagakerjaan

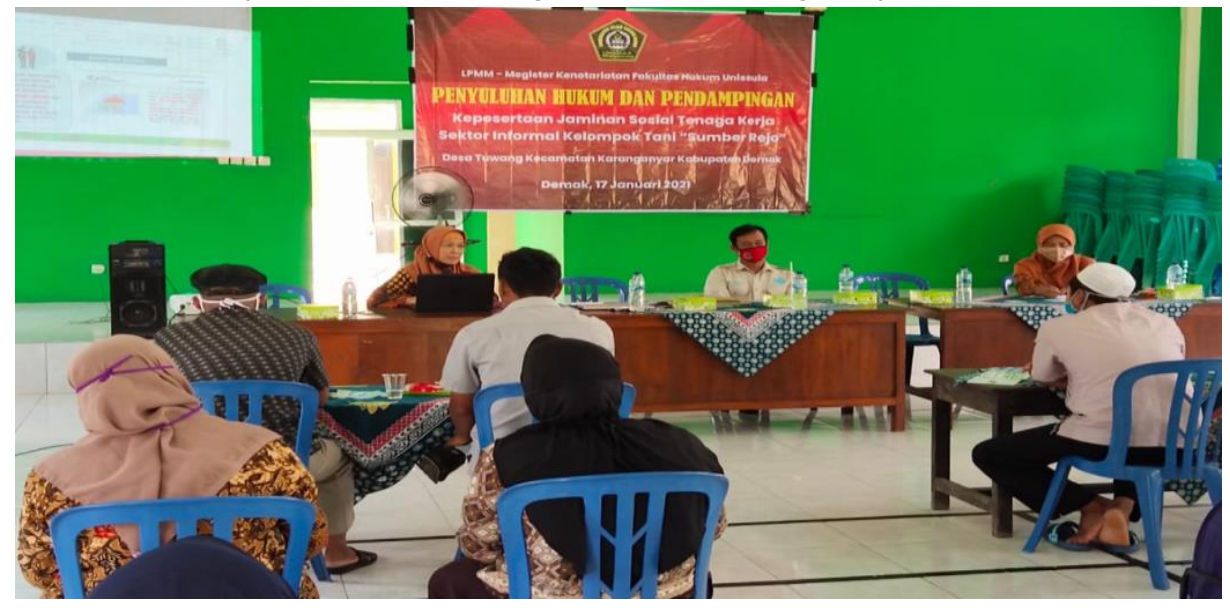

Gambar 1. Penyuluh sedang menyampaikan materinya ke peserta di Aula Balai Desa Tuwang Kecamatan Karanganyar Kabpaten Demak 


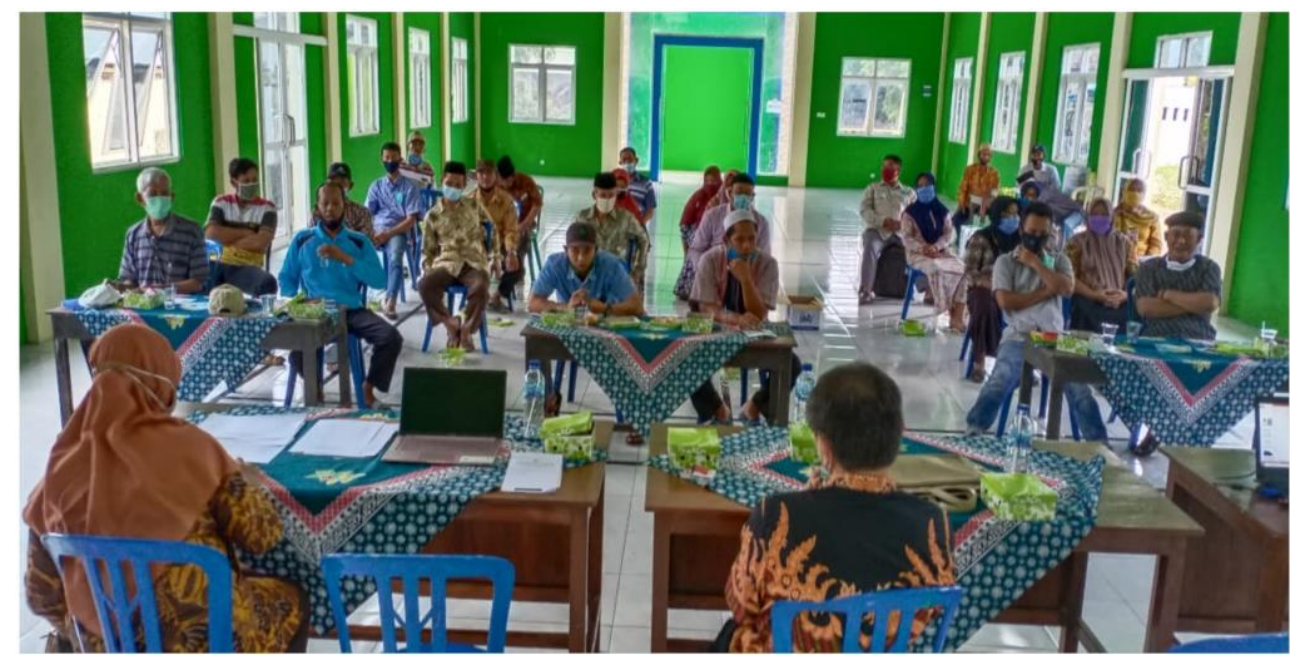

Gambar 2. Peserta Penyuluhan Hukum dan Pendampingan Kepesertaan Jaminan Sosial Tenaga Kerja Sektor Informal Kelompok Tani "Sumber Rejo"

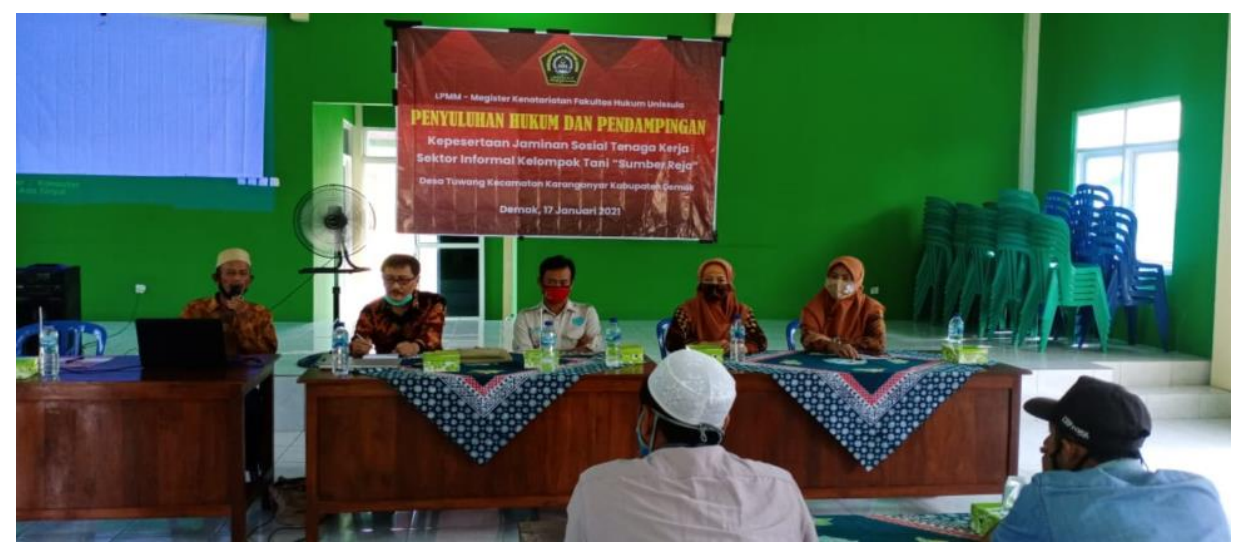

Gambar 3. Sambutan dari Ketua kelompok Tani "Sumber Rejo", bapak Fatkur Rohman dalam acara Penyuluhan Hukum dan Pendampingan Kepesertaan Jaminan Sosial Tenaga Kerja Sektor Informal Kelompok Tani

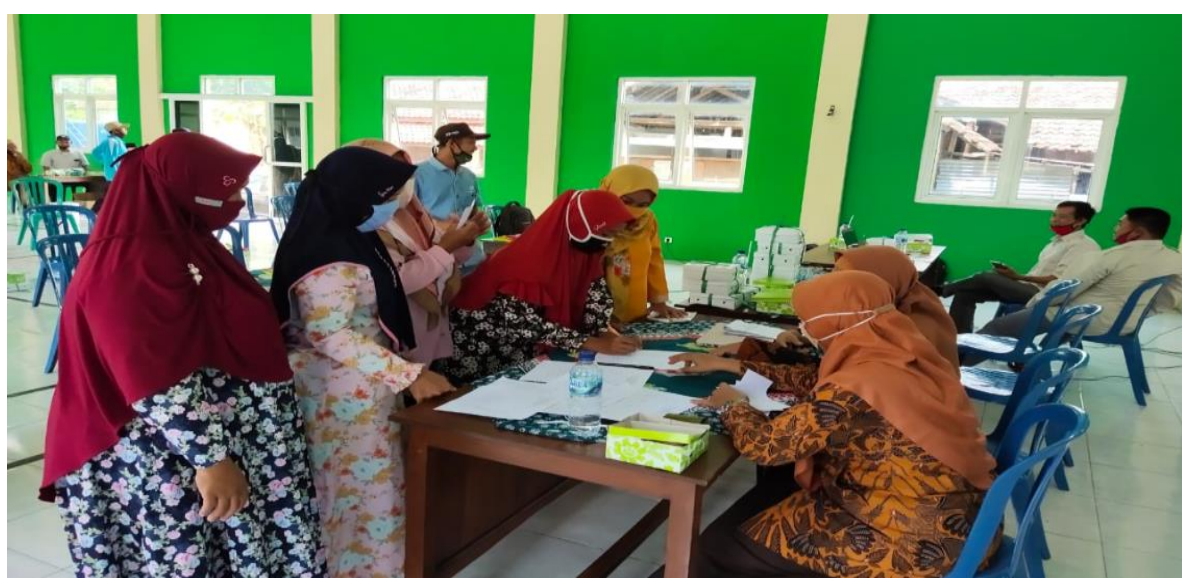

Gambar 4. Peserta sedang menyelesaikan administrasi Penyuluhan Hukum dan Pendampingan Kepesertaan Jaminan Sosial Tenaga Kerja Sektor Informal Kelompok Tani "Sumber Rejo" 


\section{SIMPULAN}

Masih minim pengetahuan, pemahaman dan kesadaran para petani untuk menjadi peserta jaminan sosial ketenagakerjaan, hal ini dikarenakan tidak adanya sosialisasi dari BPJS Ketenagakerjaan. Secara keseluruhan, peserta semangat mengikuti kegiatan pengabdian masyarakat dan menyampaikan pertanyaan-pertanyaan dan pendapatnya dengan baik, pola berpikir para peserta cukup terbuka dan fleksibel. Suasana kegiatan cukup semarak dan 'hidup'. Para peserta dengan hidmat mengikuti jalannya acara dan berani mengemukakan pendapatnya secara terbuka. Secara keseluruhan para peserta menyatakan kegiatan pendampingan dan penyuluhan hukum menarik, menambah pengetahuan dan membuka wawasan tentang jaminan sosial ketenagakerjaan. Materi penyuluhan tentang jaminan sosial ketenagakerjaan sangat bermanfaat bagi peserta untuk mendapatkan perlindungan dan keselamatan kerja dalam petani menjalankan pekerjaannya. Kegiatan ini dapat digunakan sebagai sarana silaturahmi dan promosi Universitas Islam Sultan Agung dengan masyarakat, sekaligus juga sebagai perwujudan tanggungjawab sosial Lembaga Pendidikan Tinggi dalam menjalankan Tri Darma Perguruan Tinggi.

\section{SARAN}

Kegiatan pengabdian masyarakat dapat dilakukan dengan lebih baik dan sistimatis di setiap wilayah dan diutamakan yang dekat dengan lingkungan Unissula. Sosialisasi, penyuluhan hukum dan pendampingan sangat bermanfaat diberikan kepada masyarakat dalam berbagai hal, seperti edukasi nilai-nilai Islam dalam berbagai aspek kehidupan masyarakat, pemahaman hukum, menanamkan nasionalisme, wawasan kebangsaan, pendidikan karakter, edukasi pola hidup sehat, pemberdayaan ekonomi masyarakat, mempersiapkan generasi khoiro ummah, dan lain-lain. Perlu meliibatkan unsur dari Dinas Pemerintah Daerah setempat dan yang terkait, dalam rangka meningkatkan kesejahteraan masyarakat petani agar program jaminan sosial ketenagakerjaan dapat direncanakan secara baik dan terpadu.

\section{UCAPAN TERIMA KASIH}

Dalam pelaksanaan penyuluhan dan pendampingan ini, kami sebagaai Tim Pengabdian Masyarakat Universitas Islam Sultan Agung (UNISSULA) mengucapkan terima kasih kepada Rektor Universitas Islam Sultan Agung (UNISSULA), Ketua Lembaga Penelitian dan Pengabdian Masyarakat (LPPM) UNISSULA, Dekan FH UNISSULA, pihak Mitra, yaitu kepala desa dan perangkat Desa, Ketua Kelompok Tani "Sumber Rejo" beserta anggotanya dari Desa Tuwang, Kecamatan Karanganyar, Kabupaten Demak. serta pihak terkait lain yang telah membantu terselenggaranya kegiatan ini.

\section{DAFTAR PUSTAKA}

Ali Hidayat, (2017), Pengertian BPJS Ketenagakerjaan: Program dan Manfaatnya, https://www.intanblog.com/pengertian-bpjs-ketenagakerjaan/.

Andre, (2020), BPJS, https://portal-uang.com/bpjs/.

Badan Pusat Statistik, https://www.bps.go.id/pressrelease/2020/11/05/1673/agustus-2020-tingkat-pengangguran-terbuka--tpt--sebesar-7-07-persen.html. 
Bukan Penerima Upah, https://www.bpjsketenagakerjaan.go.id/page/program/Bukan-PenerimaUpah-(BPU).html.

Edy Nurcahyo, dkk., (2020), Penyuluhan Hukum Tentang Bahaya Narkoba Di SMA Negeri 4 Pasarwajo Kabupaten Buton, Empowerment: Jurnal Pengabdian Masyarakat, e-ISSN 2598-2052, Vol. 03 Nomor 02.2020.

https://www.bpjsketenagakerjaan.go.id/page/Program-Jaminan-Hari-Tua-(JHT).html.

Lifepal, (2020), BPJS Ketenagakerjaan: Program, Peserta, dan Cara Cek Saldo [Terbaru], https://lifepal.co.id/media/program-bpjs-ketenagakerjaan/\#Siapa_saja_yang_menjadi_ peserta_BPJS_Ketenagakerjaan.

Maimun, (2004), Hukum Ketenagakerjaan Suatu Pengantar, PT. Pradnya Paramita, Jakarta.

\section{Peraturan Perundang-Undangan}

Undang-Undang Dasar Negara Republik Indonesia Tahun1945.

Undang-Undang Republik Indonesia Nomor 3 Tahun 1992 tentang Jaminan Sosial Tenaga Kerja.

Undang-Undang Republik Indonesia Nomor 39 Tahun 1999 tentang Hak Asasi Manusia.

Undang-Undang Republik Indonesia Nomor 13 Tahun 2003 tentang Ketenagakerjaan.

Undang-Undang Republik Indonesia Nomor 40 Tahun 2004 tentang Sistem Jaminan Sosial Nasional.

Undang-Undang Republik Indonesia Nomor 24 Tahun 2011 tentang Badan Penyelenggara Jaminan Sosial (UU BPJS).

Peraturan Menteri Tenaga Kerja dan Transmigrasi Nomor 24 Tahun 2006 tentang Pedoman Penyelenggaraan Program Jaminan Sosial Tenaga Kerja bagi Tenaga Kerja yang Melakukan Pekerjaan di Luar Hubungan Kerja. 